\title{
Hidrojen Peroksit ve Nitrik Oksit İlişkisinin Bitkilerde Abiyotik Stres Toleransındaki Rolü
}

\author{
Fahriye ÖCAL ÖZDAMAR ${ }^{1}$ Gökçen BAYSAL FURTANA ${ }^{1} \quad$ Ş. Şebnem ELLİALTIOĞLU² \\ ${ }^{*}$ Rukiye TIPIRDAMAZ3
}

\author{
${ }^{1}$ Gazi Üniversitesi Fen Fakültesi Biyoloji Bölümü, Ankara \\ ${ }^{2}$ Ankara Üniversitesi Ziraat Fakültesi Bahçe Bitkileri Bölümü, Ankara \\ ${ }^{3}$ Hacettepe Üniversitesi Fen Fakültesi Biyoloji Bölümü, Ankara \\ *Sorumlu yazar e-posta (Corresponding author e- mail): tuz@hacettepe.edu.tr
}

Geliş Tarihi (Received): 17.03.2016

Kabul Tarihi (Accepted): 12.04.2016

\section{Öz}

Hidrojen peroksit $\left(\mathrm{H}_{2} \mathrm{O}_{2}\right)$ ve Nitrik oksit (NO), çeşitli organizmalarda önemli etkileri bulunan sinyal iletim molekülleridir. Son 20 yıldır yapılan yoğun çalışmalara rağmen, abiyotik stres toleransında bu iki molekülün birbirleriyle olan etkileşimlerinin rolü ve oluşturdukları sinyallerin biyolojik süreçlerle ilişkileri konusundaki bilgiler günümüzde de sınırlı düzeydedir. Bu makalede bitkilerin kuraklık, tuzluluk, aşırı sıcaklık, UV ışığı ve ağır metaller gibi abiyotik strese tepkide $\mathrm{H}_{2} \mathrm{O}_{2}$ ve $\mathrm{NO}$ etkileşiminin muhtemel rolleri biyosentez, gen ifadesi ve protein aktiviteleri düzeyinde son literatür verileri ışığında araştırılmıştır. Ayrıca bitkilerde abiyotik stres yanıtlarında yer alan diğer sinyal iletim yolakları ile $\mathrm{H}_{2} \mathrm{O}_{2}$ ve NO'nun arasındaki etkileşimler tartışılmıştır.

Anahtar Kelimeler: Abiyotik stres, nitrik oksit, hidrojen peroksit, sinyal iletimi

\section{The Role of the Relationship between Hydrogen Peroxide and Nitric Oxide in Plant Tolerance to Abiotic Stresses}

\begin{abstract}
Hydrogen peroxide $\left(\mathrm{H}_{2} \mathrm{O}_{2}\right)$ and Nitric oxide (NO) are signalling molecules that play an important role in different organisms. Even though intensive research in the past two decades, knowledge about the role of these two molecules interact with each other in abiotic stress tolerance and the relationship with biological processes aren't completely elucidated yet. In this paper, $\mathrm{H}_{2} \mathrm{O}_{2}$ and $\mathrm{NO}$ cross-talk and possible role in plant responses to abiotic stresses such as drought, salinity, extreme temperatures, UV irradiation and heavy metals at the level of biosynthesis and gene expression and protein activities are investigated in light of recent literature. In addition, the cross-talk between $\mathrm{H}_{2} \mathrm{O}_{2}$ and $\mathrm{NO}$ with other signalling pathways in the regulation of abiotic stress responses in plants is also discussed.
\end{abstract}

Keywords: Abiotic stress, nitric oxide, hydrogen peroxide, signaling

\section{Giriş}

A biyotik stres koşullarında bitkinin yaşamsal faaliyetleri yavaşlamakta, su alınımı azalıp buna bağlı olarak stomalar kapanmaktadır. Bitkinin $\mathrm{CO}_{2}$ alınımı azaldığından, yeterli $\mathrm{CO}_{2}$ bulamayan fotosentetik elektronlar $\mathrm{O}_{2}$ molekülüne aktarılmakta ve sonuçta aktive edilmiş ve toksik etkisi olan süperoksit radikalleri $\left(\mathrm{O}_{2}{ }^{-}\right)$oluşmaktadır. Aşırı miktarda biriken süperoksit radikali $\left(\mathrm{O}_{2 \cdot}^{-}\right)$, hidrojen peroksit $\left(\mathrm{H}_{2} \mathrm{O}_{2}\right)$ ve hidroksil radikali $(\mathrm{OH}$.) ile birlikte singlet oksijeni $\left({ }^{1} \mathrm{O}_{2}\right)$ de içine alan reaktif oksijen türlerini (Reactive Oxygen Species:
ROS) üreterek oksidatif strese, sonuçta oksidatif hasara neden olmaktadır (Mittler et al. 2002; Mittler et al. 2004). Serbest radikaller olarak bulunan ROS'lar süperoksid $\left(\mathrm{O}_{2}\right)$, hidroperoksil $\left(\mathrm{HO}_{2}.\right)$, hidroksil $(. \mathrm{OH})$, peroksil (ROO.), alkoksil (RO.) iken; radikal olmayan ROS'lar hidrojen peroksit $\left(\mathrm{H}_{2} \mathrm{O}_{2}\right)$, tekli oksijen $\left(\mathrm{O}_{2}\right)$, ozon $\left(\mathrm{O}_{3}\right)$, hipokloröz asit $(\mathrm{HOCl})$ olarak tanımlanmaktadır. Neredeyse bütün abiyotik streslerde özellikle kloroplast, mitokondri ve peroksizomlarda üretilen bu serbest radikaller ile diğer oksidantlar, protein ve klorofilde 
tahribata, membran lipidlerinde peroksidasyona neden olarak hücre zarında hasara yol açmaktadır. Bu hasar hücre ölümüne kadar gidebilmektedir (Tanou et al. 2009a).

Diğer yandan, nitrik oksit'ten (NO) türevlenen dinitrojen trioksit $\left(\mathrm{N}_{2} \mathrm{O}_{3}\right)$, nitrojen dioksit $\left(\mathrm{NO}_{2}\right)$, peroksinitrit (ONOO-), Snitrozothioller (RSNOs), S-nitrosoglutatyon (GSNO) gibi bileşikleri tanımlamak için de reaktif nitrojen türleri (Reactive Nitrogen Species: RNS) terimi kullanılmaktadır (Halliwell and Gutteridge, 2007). "Oksidatif stres" kavramına analog bir biçimde ortaya çıkan "Nitrosatif stres" RNS bileşiklerinin toksik fizyolojik reaksiyonlar ile kontrolsüz ve aşırı üretimi anlamına gelmektedir (Klatt and Lamas 2000). ROS'lar gibi RNS'lerin de aşırı miktarları; DNA, lipitler, proteinler ve karbonhidratlara zarar vererek hücresel fonksiyonların bozulmasına neden olmaktadır. Radikal olarak bulunan RNS'ler nitrik oksit (NO), nitrik dioksit $\left(\mathrm{NO}_{2}\right)$, nitrat radikali $\left(\mathrm{NO}_{3}\right)$ iken; radikal olmayan RNS'ler nitröz asit $\left(\mathrm{HNO}_{2}\right)$, nitrozonyum katyonu $\left(\mathrm{NO}^{+}\right)$, nitroksil anyonu (NO-), peroksinitrit (ONOO-), peroksinitröz asit $(\mathrm{ONOOH})$, alkil peroksinitritler (ROONO), dinitrojen tetroksit $\left(\mathrm{N}_{2} \mathrm{O}_{4}\right)$, dinitrojen trioksit $\left(\mathrm{N}_{2} \mathrm{O}_{3}\right)$, nitronyum (Nitril) iyonu $\left(\mathrm{NO}_{2}{ }^{+}\right)$olarak sıralanmaktadırlar.

Reaktif Oksijen Türleri (ROS) ve Reaktif Nitrojen Türleri (RNS), bitkilerde hücresel sinyal sistemlerinin temelini oluşturan anahtar moleküllerdendir. Bitkiler temel fizyolojik ve hücresel süreçler sırasında hem ROS hem de RNS'leri, sinyal iletim molekülleri olarak kullanmaktadırlar (Blokhina and Fagerstedt 2010). Hücre biyolojisinin birçok aşamasında önemli görevler üstlenmelerine rağmen oksidatif ve özellikle de nitrosatif sinyal iletimi ile bu sinyallerin nasıl düzenlendikleri hakkındaki bilgiler oldukça sınırlıdır. İlk araştırmalar, biyotik streslere karşı ROS ve RNS'nin işbirliği yaptığı ve bitki koruma cevaplarını düzenlediği yönündedir. Ayrıca bulgular abiyotik stres koşullarında oksidatif ve nitrosatif sinyal iletimleri arasında güçlü karşılıklı bir etkileşim bulunduğunu göstermektedir (Molassiotis and Fotopoulo 2011).

Hidrojen peroksit $\left(\mathrm{H}_{2} \mathrm{O}_{2}\right)$, oksidatif stres sonucu oluşan reaktif oksijen türlerinin bir formudur. Biyolojik sistemlerde $\mathrm{H}_{2} \mathrm{O}_{2}$ 'nin asıl üretimi süperoksitin $\left(\mathrm{O}_{2}{ }^{-}\right)$nonenzimatik veya süperoksitdismutaz (SOD) katalizli dismutasyon reaksiyonu ile $\mathrm{H}_{2} \mathrm{O}_{2}$ 'ye dönüşmesi yoluyla olur.

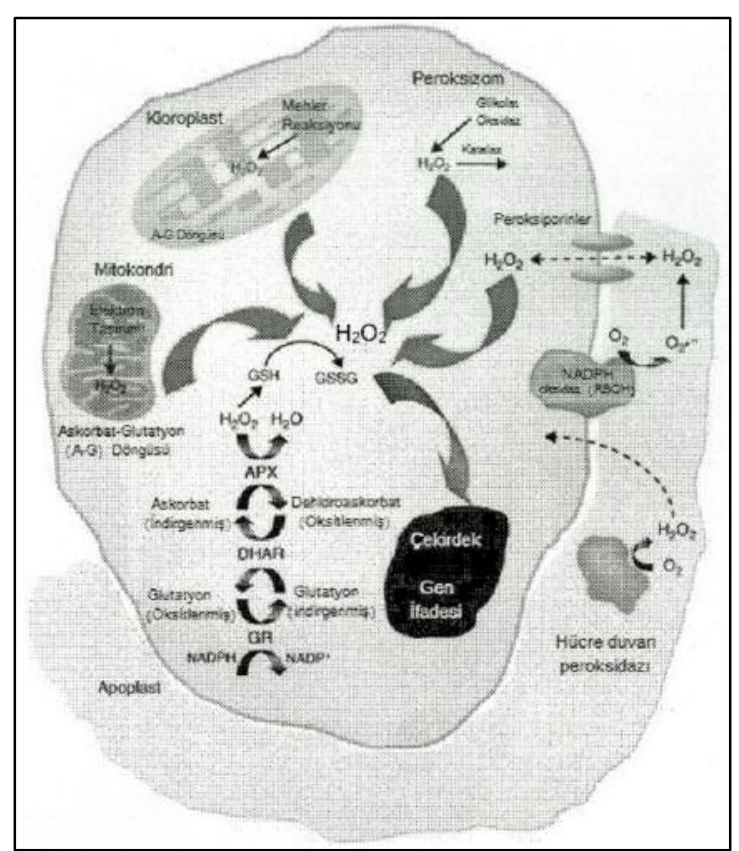

Şekil 1. Bitki Hücrelerinde $\mathrm{H}_{2} \mathrm{O}_{2}$ Oluşumu: Tuz stresi, PSII gibi PSl'i de etkilemektedir. Stomaların kapanmasına bağlı olarak $\mathrm{CO}_{2}$ miktarı sınırlandırıldığında $\mathrm{O}_{2}$, PSI tarafından da indirgenir. Calvin döngüsündeki enzimlerin inaktivasyonu döngüye katılan NADPH'ın indirgenmesini engeller. PSI'deki ferrodoksin, ortamda indirgeyecek NADP ${ }^{+}$ bulamayınca elektronunu Ferrodoksin NADP redüktaz (FNR) yerine $\mathrm{O}_{2}$ 'e aktarır ve $\mathrm{O}_{2}, \mathrm{H}_{2} \mathrm{O}_{2}$ 'e dönüştürülür. Buna Mehler reaksiyonu adı verilir. GSH: Indirgenmiş Glutatyon, GR: Glutatyon Redüktaz, DHAR: Dehidroaskorbat Redüktaz, GSSG: Okside olmuş Glutatyon (Neill et al. 2002c).

Figure 1. The $\mathrm{H}_{2} \mathrm{O}_{2}$ Generation in Plant Cells (Neill et al, 2002c).

Bitkilerde $\quad \mathrm{H}_{2} \mathrm{O}_{2}$, kloroplastlarda Mehler reaksiyonu sırasında, mitokondride elektron taşınımı sırasında, peroksizomlarda ise fotorespirasyon sırasında oluşur. $\mathrm{H}_{2} \mathrm{O}_{2}$ üretiminin bir diğer yolu da hücre zarına yerleşmiş NADPH oksidaz gibi enzimlerle enzimatik yolla gerçekleşir (Ślesak et al. 2007). $\mathrm{H}_{2} \mathrm{O}_{2}$ zardan kolaylıkla geçebilen bir moleküldür ve muhtemelen peroksiporin membran kanallarını kullanmaktadır (Şekil 1).

Bitkiler oksidatif stres altında yaşamlarını devam ettirebilmek, stresle başa çıkabilmek için ROS'ların kontrolünü ve detoksifikasyonunu sağlayan çeşitli enzimatik ve enzimatik olmayan antioksidantlara sahiptir (Çizelge 1).

Çok sayıda NO üretim yolu bilindiği halde, bunların bitkilerde sadece birkaç tanesi tam olarak aydınlatılabilmiştir. NO'nun, ya Arjinin ile Nitrat/Nitritin substrat olarak kullanıldığı farklı enzimatik yollarla (Besson-Bard et al. 2008) ya da 
nitrifikasyon/denitrifikasyon olaylarını kapsayan enzimatik olmayan yollarla sentezlendiği kabul edilmektedir (Bethke et al. 2004; Neill et al. 2003; Rockel et al. 2002). Başlıca enzimatik NO kaynakları; sitozolde yer alan nitrat redüktaz (NR), perokizomlarda yer alan nitrik oksit sentaz (NOS), plazma zarlarına bağlanmış Nitrit-NO redüktaz (Ni-NOR) ve peroksizomlarda bulunan ksantin oksiredüktaz (XOR)'dır (Corpas et al. 2004) (Şekil 2). Enzimatik olmayan NO oluşumu, $\mathrm{NO}_{2}$ 'nin, kloroplast ve apoplastik alanlarda, asidik pH'da askorbik asit ile (Henry et al. 1996) veya karotenoidler tarafından ışığa bağımlı indirgenmesi sayesinde oluşmaktadır (Cooney et al. 1994). NO sentez yolları ile ilgili ayrıntılı literatür bilgisi, Ünsal ve Arisan (2009) ile Khan et al. (2015) tarafından verilmiştir.

Gaz halinde reaktif bir serbest radikal olan NO, fizyolojik pH'da protonlanabilir ve güçlü bir lipid peroksidasyon başlatıcısı olan azotdioksiti $\left(\mathrm{NO}_{2}\right)$, hidroksil radikalini $(\mathrm{OH})$, fenilalanin, tirozin gibi aromatik halkaları, nitrolama ajanı olan nitronyum iyonunu $\left(\mathrm{NO}_{2}{ }^{+}\right.$) oluşturabilir (Halliwell 1984). Bu yüzden NO'nun sinyal iletim olaylarını başlatmasının hemen ardından, hızla ortadan kaldırıması veya metabolize edilmesi gerekmektedir (Şekil 2).

Nitrik oksit, hem hayvanlarda hem de bitkilerde ROS'lar ile aynı yer ve zamanda üretilmektedir. Oldukça hızlı ve geri dönüşümlü bir şekilde ya proteinlerin tiyol grupları ile ya da protein S- nitrozilasyonuna neden olan tripeptid glutatyon (GSH) ile tepkimeye girerek Snitrosoglutatyon (GSNO)'yu oluşturur. GSNO, hücre içi NO deposu ve hücrede konumlanmış bir NO molekülüdür. GSNO ve bunun parçalanmasını katalizleyen S-nitrosoglutatyon redüktaz (GSNOR), ROS ve RNS metabolizmaları arasında önemli anahtar moleküllerdir (Malik et al. 2011). Çözülebilir, düşük moleküler ağırlıkı antioksidantlardan biri olan glutatyon, hücrenin redoks durumunu düzenlemekten sorumludur. Bu yüzden, GSH/GSSG yani indirgenmiş ve okside olmuş glutatyon oranı, bitkinin fizyolojik durumunu, hücrenin redoks dengesini gösteren ve ROS ile RNS metabolizmaları arasındaki net bağlantıyı ortaya koyan etkili bir indikatör olarak düşünülmektedir (Foyer and Noctor 2011). Bu oran oksidatif stres koşullarında azalmaktadır.

Aynı zamanda NO; tuzluluk, düşük ve yüksek ışık, düşük ve yüksek sıcaklık, karanlık ve mekanik yaralanma gibi stres koşulları altında kalan bitkilerde, bir dizi dayanıklılık mekanizmasına aracılık etmektedir (Delledonne et al. 1998; Uchida et al. 2002; Zhao et al. 2004; 2006; 2007). Stres koşulları altında sinyal iletim yolunda görev alan NO, reaktif oksijen türleri (ROS) ile karşılıkı etkileşim halindedir. NO'nun lipid peroksidasyonunu azaltması da onun potansiyel antioksidan rolüne işaret etmektedir (Beligni and Lamattina 1999; Vraova et al. 2002).

Çizelge 1. Bitkilerde enzimatik ve enzimatik olmayan antioksidantların lokalizasyonları ve rolleri (Büyük ve ark. 2012).

Table 1. The role and localization of enzymatic and non-enzymatic antioxidants in plants (Büyük et al. 2012)

\begin{tabular}{|c|c|c|c|}
\hline & ANTIOKSIDANTLAR & GÖREVLERI & $\begin{array}{l}\text { HÜCREDEKİ } \\
\text { YERLEŞIMI }\end{array}$ \\
\hline \multirow{5}{*}{ 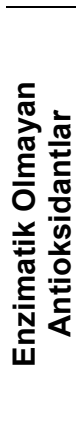 } & Askorbik Asit (Vitamin C) & $\mathrm{O}_{2}^{-}, \mathrm{OH}$ ve $\mathrm{H}_{2} \mathrm{O}_{2}$ 'yi temizler. & \multirow{4}{*}{$\begin{array}{l}\text { Kloroplast, apoplast, } \\
\text { vakuol, sitozol } \\
\text { Tüm bitki kısımlarında } \\
\text { özellikle kloroplast } \\
\text { membranlarında } \\
\text { Sitozol, vakuol } \\
\text { Sitozol, endoplazmik } \\
\text { retikulum, vakuol, } \\
\text { mitokondri }\end{array}$} \\
\hline & Tokoferoller (Vitamin E) & $\begin{array}{l}\text { Lipit peroksidasyonunu engeller, } \mathrm{O}_{2}^{-} \text {ve } \mathrm{OH}^{\prime} \mathrm{i} \\
\text { temizler. }\end{array}$ & \\
\hline & Karotenoidler & Peroksil radikalleri ile $\mathrm{O}_{2}^{-}$ve $\mathrm{OH}^{\prime} \mathrm{i}$ temizler. & \\
\hline & Glutatyon & $\begin{array}{l}\text { Redoks döngüsünün bir substratı olarak, } \mathrm{OH} \text { ve } \\
{ }^{1} \mathrm{O}_{2} \text { ' yi temizler. }\end{array}$ & \\
\hline & Fenolik Bileşikler & $\begin{array}{l}\text { Antioksidan özelliklerini iyi birer hidrojen veya } \\
\text { elektron vericisi olmaları, zincir kırıcı özellikleri ve } \\
\text { geçiş metalleri ile şelat oluşturmaları ile gösterirler. }\end{array}$ & Sitozol, vakuol \\
\hline \multirow{4}{*}{ 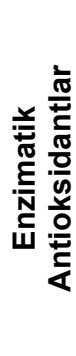 } & $\begin{array}{l}\text { Süperoksitdismutaz } \\
\text { (SOD) }\end{array}$ & $\mathrm{O}_{2}^{-{ }^{-} y i ~} \mathrm{H}_{2} \mathrm{O}_{2}$ 'e dönüştürür & \multirow{4}{*}{$\begin{array}{l}\text { Kloroplast, sitozol, } \\
\text { mitokondri, } \\
\text { peroksizom } \\
\text { Kloroplast, sitozol, } \\
\text { mitokondri, } \\
\text { peroksizom } \\
\text { Peroksizom } \\
\text { Kloroplast, sitozol, } \\
\text { mitokondri, } \\
\text { endoplazmik retikulum }\end{array}$} \\
\hline & $\begin{array}{l}\text { Askorbat Peroksidaz } \\
\text { (APX) }\end{array}$ & $\mathrm{H}_{2} \mathrm{O}_{2}$ 'yi $\mathrm{H}_{2} \mathrm{O}$ ’ya dönüştürür. & \\
\hline & Katalaz (CAT) & $\mathrm{H}_{2} \mathrm{O}_{2}{ }^{\prime}$ yi $\mathrm{H}_{2} \mathrm{O}^{\prime}$ ya dönüştürür. & \\
\hline & $\begin{array}{l}\text { Glutatyon Peroksidaz } \\
\text { (GPX) }\end{array}$ & $\mathrm{H}_{2} \mathrm{O}_{2}$ yi ve lipit peroksitlerini etkisiz hale getirir. & \\
\hline
\end{tabular}


Çeşitli streslere maruz kalan bitkilerde hem $\mathrm{H}_{2} \mathrm{O}_{2}$, hem de $\mathrm{NO}$ yapımı uyarılmaktadır (Desikan et al. 2004). Bitkilerin stresli ortamlara dayanıklılı̆ı, oksidatif stresi tolere edebilme yetenekleri ile ilişkili olup, çevresel uyarıcılara karşı yanıtları da, $\mathrm{H}_{2} \mathrm{O}_{2}$ ve $\mathrm{NO}$ sinyal yolakları ile koordineli bir biçimde yürütülmektedir (Şekil 3).

Son çalışmalar $\mathrm{H}_{2} \mathrm{O}_{2}$ ve NO'nun bitkilerde birbirini etkileyen sinyal molekülleri olarak işlev gördüğünü; bulundukları ya da uygulandıkları miktarlara bağlı olarak toksik madde veya sinyal molekülü olarak görev yaptıklarını göstermektedir (Neill et al. 2002b; 2003; Wendehenne et al. 2004; Delledonne 2005; Khan 2015). Normal veya abiyotik stres altındaki bitkilerde dışsal olarak uygulanan NO'nun $\mathrm{H}_{2} \mathrm{O}_{2}$ miktarını azalttığına dair pek çok çalışma mevcuttur. Tuzluluk (Li et al. 2008), düşük sıcaklık (Liu et al. 2010a), ağır metal (Cui et al. 2010) gibi çeşitli abiyotik streslerde bitkide artan $\mathrm{H}_{2} \mathrm{O}_{2}$ miktarının dıştan uygulanan NO tarafından azaltıldığı bildirilmiştir.

$\mathrm{Bu}$ makalede, bitkilerin maruz kaldığı, özellikle tuzluluk, kuraklık, ekstrem sıcaklıklar, UV ışığı ve ağır metaller gibi abiyotik streslere yanıtlarında, $\mathrm{H}_{2} \mathrm{O}_{2}$ ve NO'nun hem biyosentez hem de gen ifadesi ve protein aktivitelerinin düzenlenmesi düzeyinde, birbirleriyle etkileşimlerinin muhtemel rolleri konusundaki bilgiler son literatür ışığında verilmiştir. Ayrıca $\mathrm{H}_{2} \mathrm{O}_{2}$ ve $\mathrm{NO}$ etkileşiminin bitkilerde abiyotik stres yanıtlarında yer alan diğer sinyal iletim yolakları ile ilişkileri tartışılmıştır.

\section{2. $\mathrm{H}_{2} \mathrm{O}_{2}$ ve NO İlişkisinin Farklı Abiyotik Streslerdeki Rolü}

\subsection{Tuz Stresi}

Toprak tuzluluğu, küresel ölçekte ürün verimini ve besin güvenliğini etkileyen önemli faktörlerden biridir. Tuzluluk, bitkiyi ozmotik strese maruz bırakıp, iyon dengesini bozarak çeşitli metabolik olayları etkilemekte ve sonuçta bitki büyüme ve gelişmesini engellemektedir. Bitkilerin bu ozmotik ve iyonik stresler karşısında verdiği yanıtlar ise oldukça karmaşık olup çok sayıda gen ağı ve metabolik olayı içermektedir (Abogadallah, 2010). $\mathrm{H}_{2} \mathrm{O}_{2}$ ve NO üretiminin değiştirilmesi, bitkinin tuz stresine adaptasyonunu sağlayan mekanizmalar arasında sayılabilir (Avsian-Kretchmer et al. 2004; Zhang et al. 2006; Zhao et al. 2007). Tuz stresi hücrelerde genellikle $\mathrm{H}_{2} \mathrm{O}_{2}$ 'yi de içine alan ROS üretimini artırdığı bilinirken, NO üretimi üzerindeki etkisi tam olarak bilinmemektedir. Zhao et al. (2007), $\mathrm{NaCl}$ uygulamasının Arabidopsis'te NO-ilişkili AtNOA1 geninin ifadesini baskılayarak hücre içi NO miktarında azalmaya neden olduğunu bildirmiştir. Buna karşın çeltikte AtNOA1'in homoloğu olan OsNOA1 geninin ifadesi, tuz stresi ile birlikte artmıştır (Qiao et al. 2009). Bu farklılık, tuz stresine cevapta farklı türlerin kendilerine özgü NO-sentezleyici ya da düzenleyici sistemleri olduğunu göstermektedir.

Tuza tolerans mekanizmalarında önemli bir parametre olan $\mathrm{Na}^{+} / \mathrm{K}^{+}$dengesi için $\mathrm{H}_{2} \mathrm{O}_{2}$ ve $\mathrm{NO}$ gereklidir. $\mathrm{NO}, \mathrm{Na}^{+} / \mathrm{K}^{+}$oranını azaltarak tuz toleransını artırıcı yönde etki yapmaktadır. Bunu da $\mathrm{H}^{+}$-ATPaz-bağlantılı genler ile NO-uyarımlı hücre zarı $\mathrm{Na}^{+} / \mathrm{H}^{+}$antiportır ifadeleri, hücre zarı ve vakuolar $\mathrm{H}^{+}$-ATPaz ve $\mathrm{H}^{+}$-PPaz aktivitelerindeki artı̧a bağlı olarak gerçekleştirmektedir (Zhao et al. 2004; Zhang et al. 2006; Wang et al. 2009). Mazid et al. (2011), tuz stresi koşullarında NO'nun $\mathrm{H}_{2} \mathrm{O}_{2}$ üretimini düzenlediğini ifade ederek, hücre zarı $\mathrm{H}$ ATPaz'ların aktivitesini düzenlemek için, $\mathrm{H}_{2} \mathrm{O}_{2}$ 'nin metabolik yolda NO'dan daha sonra yer alabileceğini belirtmişlerdir.

Nitrik oksit donörü sodyumnitropurisit (SNP)'in dışsal olarak uygulanması; çeltik (Uchida et al. 2002), acı bakla (Kopyra and Gwóźdź 2003) ve hıyar (Fan et al. 2007) fidelerinde tuzluluktan kaynaklanan oksidatif hasarı önemli ölçüde azaltmış, tuz stresi etkisindeki mısır fidelerinde de fide gelişimini ve kuru ağırlığı artırmıştır (Zhang et al. 2007). Tuz stresi, hücrelerde $\mathrm{H}_{2} \mathrm{O}_{2}$ miktarını artırarak oksidatif stres oluşumunu uyarmaktadır. Bununla birlikte, dışarıdan uygulanan $\mathrm{H}_{2} \mathrm{O}_{2}$, içsel $\mathrm{H}_{2} \mathrm{O}_{2}$ düzeyini artırıp, sonrasında bir sinyal molekülü işlevi görebilir (Qiao et al. 2014). Nitekim buğday tohumlarına $\mathrm{H}_{2} \mathrm{O}_{2}$ uygulanması, fide döneminde tuza tolerans özelliğini artırmıştır (Wahid et al. 2007).

Tuz toleransında $\mathrm{H}_{2} \mathrm{O}_{2}$ ve NO'nun olumlu etkilerinin olası mekanizmaları birkaç çalışmada incelenmiştir. Tanou et al. (2009a), turunçgil bitkilerinin tuza alışması sürecinde $\mathrm{H}_{2} \mathrm{O}_{2}$ ve $\mathrm{NO}$ sinyal iletim yolaklarının örtüştüğünü belirtmektedir. Tuz stresi öncesinde $\mathrm{H}_{2} \mathrm{O}_{2}$ ile SNP nin birlikte uygulandığı gruplarda, uygulama yapılmamış kontrol grubuna göre yapraklarda tuzluluk nedeniyle artan protein karbonilasyonu azalmış ve S-nitrozile edilmiş protein miktarları değişmiştir (Tanou et al. 2009b). 


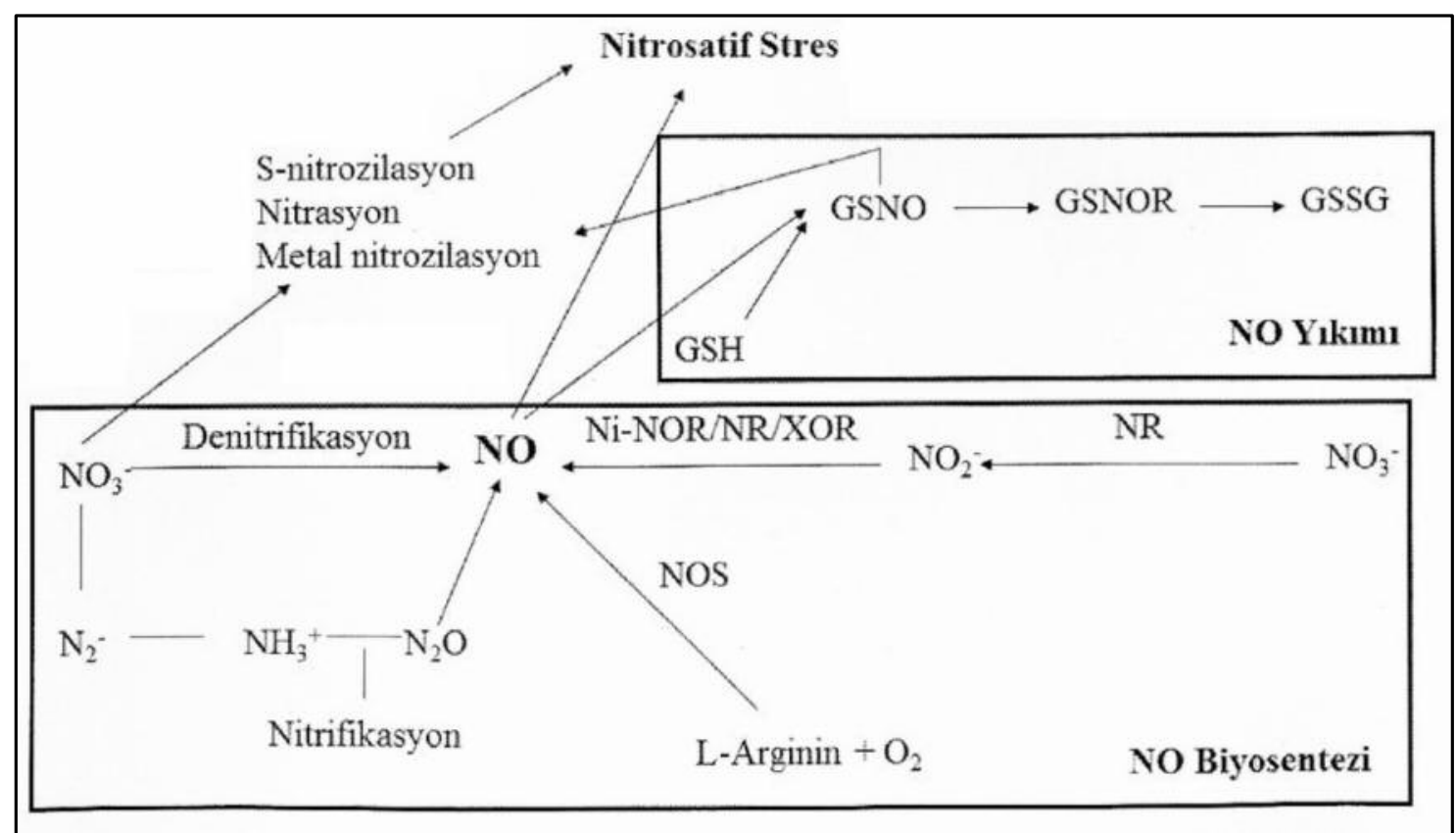

Şekil 2. Bitki hücrelerinde NO üretimi. Nitrattan enzimatik NO üretimi, Nitrat redüktaz (NR), Nitrit-NO redüktaz (Ni-NOR), Ksantin Oksidaz (XOR) ve Nitrik oksit sentaz (NOS) enzimleri ile gerçekleştirilir. Enzimatik olmayan NO üretimi ise nitrifikasyon/denitrifikasyon olaylarını kapsamaktadır. Bitkilerde Nitrik Oksitin ortadan kaldırılması ve detoksifikasyonu GSNO: S-nitrosoglutatyon, GSH: İndirgenmiş Glutatyon, GR: Glutatyon Redüktaz, GSNOR: S-nitrosoglutatyon redüktaz, GSSG: Okside olmuş Glutatyon.

Figure 2. The NO generation in plant cells.

Tuz stresi koşullarında $\mathrm{H}_{2} \mathrm{O}_{2}$ ve $\mathrm{NO}$ sinyal iletim ilişkisi, Arabidopsis'in in vivo NOS aktivitesi eksik ve NO miktarı azaltılmış Atnoa1 mutantında değerlendirilmiştir (Zhao et al. 2007). Atnoa1 bitkilerinin hem kontrol, hem de stres koşulları altında yabani tip bitkilerden daha fazla miktarda $\mathrm{H}_{2} \mathrm{O}_{2}$ 'ye sahip olduğu, böylece bu bitkilerin oksidatif streslere karşı yabani tiplerden daha hassas yapıda oldukları anlaşılmıştır (Zhao et al. 2007). Çeltik bitkisinde OsNOA1'in aşırı ifadesi arka planda $\mathrm{Na}^{+} / \mathrm{K}^{+}$ oranını azaltarak, Atnoa1'deki tuz hassasiyetini düzeltmiştir (Qiao et al. 2009).

Tuz stresinde büyütülen iki mısır (Zea mays L.) çeşidinde tohum ve fide döneminde nitrik oksit ve thioureanin birlikte dışarıdan uygulanması, tuzun oluşturduğu olumsuz etkileri ortadan kaldırarak tuza dayanıklılığı artırmıştır (Kaya ve ark. 2015).

\subsection{Kuraklık Stresi}

Kuraklık stresinin $\mathrm{H}_{2} \mathrm{O}_{2}$ ve/veya $\mathrm{NO}$ oluşumunu teşvik ettiği çok sayıdaki bitki türünde gösterilmiştir (Leshem and Haramaty 1996; Kolbert et al. 2005; Gould et al. 2003; Jubany-Marí et al. 2010). Dehidrasyon stresinin mısır fidelerinde NOS benzeri bir aktivite ile hücrelerden NO salınımını artırdığı belirlenmiştir (Hao et al. 2008).
Bitkilerin kuraklık cevaplarında $\mathrm{H}_{2} \mathrm{O}_{2}$ ve $\mathrm{NO}$ arasındaki karşılıklı sinyal alışverişi araştııımıştır. Bermuda çimi bitkisinde kuraklık stresine karşı ABA'nın koruyucu etkisine ya $\mathrm{H}_{2} \mathrm{O}_{2}$, ya da $\mathrm{NO}$ aracılık etmektedir. Burada, SOD ve CAT aktivitelerinin ABA ile uyarılmasında NO'nun, metabolik yola $\mathrm{H}_{2} \mathrm{O}_{2}$ 'den daha sonra katıldığı gösterilmiştir ( $\mathrm{Lu}$ et al. 2009).

Liao et al. (2012) da, kuraklık stresi koşullarında kadife çiçeği bitkisinde hem NO, hem de $\mathrm{H}_{2} \mathrm{O}_{2}$ 'in adventif kök oluşumunda hayati rol oynadığını belirlemişlerdir. Araştırıcılar kuraklık stresi koşullarında uygulanan $\mathrm{NO}$ ve $\mathrm{H}_{2} \mathrm{O}_{2}$ 'nin uygun dozlarının mezofil hücrelerinin yapısını koruduğunu ve kadife çiçeği eksplantlarında, kuraklığın karbonhidrat ve nitrojen birikimi üzerindeki negatif etkilerini ortadan kaldırdığını belirlemişlerdir (Liao et al. 2012).

\subsection{UV stresi}

UV-B ışınlarının (250-320 nm) varlığı çoğunlukla, stratosferin ozon tabakasındaki hasardan kaynaklanmaktadır. Yaşama ortamlarındaki UV-B radyasyonu, otsu bitkilerde $\mathrm{H}_{2} \mathrm{O}_{2}$ miktarını artırıp, tilakoid membran proteinlerinin oksidasyonu sonucunda zararlı etkilere neden olmaktadır (Shi et al. 2005). UV-B ışınları, Arabidopsis'te $\mathrm{NO}$ ve $\mathrm{H}_{2} \mathrm{O}_{2}$ üretiminin 
artışıyla gerçekleşen stoma kapanmasına neden olmaktadır. UV-B, NO moleküllerinin yapımını NOS aktivitesi ile uyarmaktadır (He et al. 2005). Wang et al. (2006), UV-B radyasyonuna maruz kalmış mısır yapraklarında savunma yanıtlarının verilmesinde $\mathrm{NO}$ ve $\mathrm{H}_{2} \mathrm{O}_{2}$ 'nin, etilen biyosentezinde sinerjistik etkiye sahip olduğunu belirtmişlerdir. Aynı araştırıcılar NO biyosentezinin NR aktivitesi ile değil, NOS aktivitesi ile arttığını ve ROS artışının da NADPH oksidazdan kaynaklanmadığını ifade etmektedirler.

Tossi et al. (2009), yabani tip ve ABA-eksik mısır mutantlarının yapraklarında, UV-B ile ABAuyarımlı NO sentez yolu arasında bir ilişki bulunduğunu belirlemişlerdir. Bu çalışmaların sonuçları, UV-B Işınlarının ABA konsantrasyonunu artırdığını, bunun da NADPH oksidaz'ı aktive ederek, $\mathrm{H}_{2} \mathrm{O}_{2}$ oluştuğunu göstermiştir. Aynı zamanda NOS-benzeribağımlı mekanizmanın da NO yapımını artırarak hücre homeostazisini koruduğunu, böylece UVB'nin oksidatif etkisinden kaynaklanan hücre hasarının azaltıldığını göstermiştir.

Santa-Cruz et al. (2010), NO'nun bitkileri klorofil kaybı, $\mathrm{H}_{2} \mathrm{O}_{2}$ ve $\mathrm{O}_{2}-$ birikimi ve iyon sızıntısı gibi oksidatif hasarlara karşı koruduğunu, NO'nun nitrat redüktaz (NR) aktivitesi yerine NOS-benzeri bir aktivite sonucu oluştuğunu, bunun da antioksidatif özelliklere sahip bir hemooksijenaz olan $\mathrm{HO}-1$ 'in uyarılması için gerekli olduğunu açıklamışlardır. Araştırıcılar, UV-B altında NO'nun HO-1'i artma yönünde düzenleyen sinyal yolu ile ilişkili olduğunu; NO ve ROS arasındaki dengenin, bitkinin oksidatif streslere karşı antioksidant cevaplarının ortaya çıkarılmasında önemli olduğunu belirtmişlerdir. Shi et al. (2005) tarafından NO'nun dıştan uygulandığı bezelye yapraklarında UV-B ile uyarılan $\mathrm{H}_{2} \mathrm{O}_{2}$ üretiminin $\mathrm{NO}$ tarafından baskılandığı gösterilmiş ve tilakoid zarlarda UVB'nin yol açtığı oksidatif zarara karşı NO'nun koruyucu rolü ortaya konmuştur.

\subsection{Sıcaklık Stresleri}

Bitkilerde yüksek sıcaklık (sıcaklık stresi) oksidatif stres, membran hasarı, protein bozulması, enzim inaktivasyonu ve DNA hasarına neden olurken (Suzuki and Mittler, 2006), düşük sıcaklıklar (soğuk stresi) bitkilerde ROS-dengesi ile biyokimyasal ve fizyolojik birçok süreçte önemli değişikliklere neden olmaktadır (Zhao et al. 2009).

Sıcaklığın bitki hücrelerinde $\mathrm{H}_{2} \mathrm{O}_{2}$ oluşumuna ve oksidatif streslere neden olduğu (Larkindale and Knight 2002); $\mathrm{H}_{2} \mathrm{O}_{2}$ oluşumunun, sıcaklık sinyalinin iletilmesine, sıcaklık şoku proteinlerinin (HSPs) ve metabolik yolda bunlardan sonra gelen diğer proteinlerin ifade edilmesini sağladığı bilinmektedir (Volkov et al. 2006; Königshofer et al. 2008). Arabidopsis'e ait süspansiyon kültürlerindeki hücrelerde ve fidelerde yüksek sıcaklıklarda dışarıdan $\mathrm{H}_{2} \mathrm{O}_{2}$ uygulaması HsfA2 ve küçük HSP transkripsiyonunu sağlamıştır (Volkov et al. 2006; Banti et al. 2010). Bunun aksine, yüksek sıcaklık stresi uygulanan Arabidopsis ve tütün bitkilerinde peroksit süpürücüleri veya $\mathrm{H}_{2} \mathrm{O}_{2}$ inhibitörlerinin eklenmesinin, HSP ifadesini azalttığı bildirilmiştir (Volkov et al. 2006; Königshofer et al. 2008). Peroksit süpürücülerinin eklenmesinin yüksek sıcaklık stresi altındaki bitkilerde HSP'lerin DNAbağlama yeteneğini bloke ettiği gösterilmiştir (Volkov et al. 2006). Ancak, $\mathrm{H}_{2} \mathrm{O}_{2}$ 'nin HSP'yi nasıl aktive ettiği tam olarak açıklanamamıştır.

Sıcaklık şoku sonrasında Arabidopsis ve tütün bitkilerinde (Gould et al. 2003; Xuan et al. 2010) olduğu gibi yonca hücrelerinde (Neill et al. 2003) de, endojen NO düzeylerinin arttığı bildirilmiştir. Sıcaklık stresinin Symbiodinium microadriaticum'da NO yapımını uyardığı, muhtemelen NO'nun Kaspaz benzeri bir aktivite ile hücre ölümü sinyalinin iletilmesinde rol aldığı bildirilmiştir (Bouchard and Yamasaki, 2009). Arabidopsis'in NO sentezleyemeyen Atnoa1 mutantı ile yapılan çalışmalar NO'nun termotoleransta rol aldığını göstermektedir (Xuan et al. 2010).

Sıcaklık stresine verilen yanıtlarda $\mathrm{H}_{2} \mathrm{O}_{2}$ ile NO arasındaki ilişkinin araştırıldığı çeltik fidelerinde $\mathrm{H}_{2} \mathrm{O}_{2}$ veya $\mathrm{NO}$ ön muamelesinin sadece ROS-süpürücü enzim aktivitelerini değil, aynı zamanda oksidatif stresle ilişkili genlerin ifadesini de artırdığı bildirilmiştir (Uchida et al. 2002). Düşük konsantrasyonlarda $\mathrm{H}_{2} \mathrm{O}_{2}$ veya $\mathrm{NO}$ uygulaması, çeltik bitkisi fidelerinde hayatta kalma düzeylerini artırmış olup uygulama yapılmamış kontrol bitkileriyle karşılaştırıldığında fotosistem II'nin kuantum verimini artırmıştır.

Song et al. (2006) tarafından yapılan çalışmada, yüksek sıcaklık stresi altında kültüre alınan kamış kalluslarına NO donörü olan SNP ve S-nitroz-N-asetilpenisillamin uygulaması yapıldığında; iyon sızmasındaki artışlar, büyümenin engellenmesi ve hücre canlılık oranındaki azalma önemli düzeyde gerilemiştir. Ayrıca SOD, APX, CAT ve POD gibi ROS süpürücü enzimlerin de aktivitelerini artmıştır. NO'nun, ROS süpürücü enzimleri aktive eden pozitif bir sinyal gibi işlev gördüğü yorumu yapılmıştır. 
Nitrik oksit ve/veya salisilik asit (SA) uygulanan ve ardından donma stresine maruz bırakılan buğday (Triticum aestivum L.) fidelerinde, sadece donma stresi uygulanan gruplara göre $\mathrm{H}_{2} \mathrm{O}_{2}$ ve $\mathrm{O}_{2} \cdot$ - anyonu gibi ROS'ların ve MDA'nın miktarı azalmıştır. En yüksek SOD, CAT ve POX aktiviteleri Nitrik Oksit donörü SNP'nin ve SA'nın birlikte uygulandığı gruplarda görülmüştür (Esim ve Atıcı 2015). Dışarıdan uygulanan NO'nun, donma stresine maruz kalan buğday (Esim ve ark. 2014) ve mısır (Esim ve Atıcı 2014) fidelerinde antioksidan enzim aktivitelerini uyararak soğuk toleransını artırdığı rapor edilmiştir.

\subsection{Ağır metal stresi}

Ağır metal stresleri, ROS üretimine yol açarak oksidatif hasara neden olmaktadır. Cd ve Cu gibi ağır metaller ROS birikimini üç yolla etkilemektedir: Birincisi; aşırı $\mathrm{Cd}^{2+}$, miR398 gen ifadesini uyarmakta ve sonra $\mathrm{Cu} / \mathrm{Zn} / \mathrm{SOD}$ (CSD) fonksiyonunu engelleyerek sonuçta ROS birikimini teşvik etmektedir. İkincisi; aşırı $\mathrm{Cd}^{2+}$, $\mathrm{Ca}^{2+}$ un düzenleyici işlevini engellemekte olup CSD aktivitesinin baskılanmasıyla ROS birikimine yol açmaktadır. Üçüncüsü ise; aşırı $\mathrm{Cd}^{2+}$, NADPH oksidazları aktive etmekte ve bu durum aşırı $\mathrm{H}_{2} \mathrm{O}_{2}$ yapımına neden olmaktadır (Lin and Aarts 2012).

Ağır metallerin NO üretimine olan etkisi ile ilgili çalışmalar oldukça tartışmalı olup, değişik türlerin farklı organlarında NO düzeylerinde artma ya da azalma şeklinde kendini gösterdiği bildirilmiştir (Xiong et al. 2010).

Bununla birlikte çok sayıda çalışmada, genel olarak dışarıdan uygulanan NO donörlerinin, bitkileri ağır metallerin öldürücü etkilerinden koruyucu etki yaptığı sonucuna varılmıştır (Kopyra and Gwóźdź 2003; Hu et al. 2007; Wang and Yang 2005; Tian et al. 2006; Singh et al. 2008, Zhang et al. 2008; Xiong et al. 2009; Wang et al. 2010a).

NO'nun, ağır metal stresinin yol açtığı hasarı, ROS süpürücü antioksidan miktarını ve antioksidatif enzim aktivitelerini uyararak iyileştirdiği ifade edilmiştir (Hsu and Kao, 2004). Mısır tohumlarına çimlenmeden önce uygulanan SNP $(100 \mu M)$ 'nin, antioksidan enzim aktivitelerini artırarak, Bor'un bitkide neden olduğu oksidatif hasara karşı tolerans geliştirilmesine önemli katkı sağladığı rapor edilmiştir (Esim ve Atıcı 2013).

Yapılan başka bir çalışmada, yetişme ortamına kadmiyum $(\mathrm{Cd})$ ile birlikte NO donörü SNP ile süpürücüsü $\mathrm{CPTIO}$ ilave edilerek büyütülen kadmiyuma toleransı farkı iki buğday çeşidine ait fidelerde NO, Cd ve serbest poliamin (PA) miktarlarındaki değişimler incelenmiştir. SNP uygulaması fidelerde içsel NO seviyesini artırmıştır. CPTIO uygulamasında NO seviyesi ve Cd birikimi azalırken strese karşı rol oynadığı bilinen PA seviyeleri artmıştır (Mutlu ve Yürekli 2015).

NO'nun, ağır metal toksisitesini engellemesinin diğer bir yolunun da, kök hücre duvarı bileşenlerinden pektin ve hemiselüloz miktarlarını artırarak daha fazla ağır metali ayırabilmesi olduğu belirtilmiştir (Xiong et al. 2009).

\section{3. $\mathrm{H}_{2} \mathrm{O}_{2}$ ve NO'nun Biyosentez Düzeyinde} Etkileşimleri

Tuzluluk, dehidrasyon, UV, aşırı sıcaklıklar, ağır metaller gibi abiyotik stresler ile kalsiyum iyonları, yaralanma ve fitohormonlar (ABA) gibi uyaranlar, bitkilerde $\mathrm{NO}$ ve $\mathrm{H}_{2} \mathrm{O}_{2}$ üretimini teşvik etmektedir.

$\mathrm{H}_{2} \mathrm{O}_{2}$ uygulaması yapılan Maş fasulyesinde (Lum et al. 2002) ve yabani tip Arabidopsis bitkilerinde (Wang et al. 2010c) NO üretildiği gösterilmiştir. Arabidopsis bekçi hücrelerinde, ABA-aracılı $\mathrm{NO}$ oluşumunun $\mathrm{ABA}$-uyarımlı $\mathrm{H}_{2} \mathrm{O}_{2}$ üretimine bağlı olduğu; bununla birlikte stoma bekçi hücrelerine yapılan NO uygulamasının $\mathrm{H}_{2} \mathrm{O}_{2}$ üretimini teşvik etmediği ve NO-uyarımlı stoma kapanması için $\mathrm{H}_{2} \mathrm{O}_{2}$ sentezinin gerekli olmadığı ortaya konmuştur. Antioksidantlarla veya $\mathrm{NADPH}$ oksidaz inhibitörleri ile $\mathrm{H}_{2} \mathrm{O}_{2}$ sentezinin engellenmesi, NO oluşumunu ve stoma kapanmasını önlemektedir (Bright et al. 2006). Bunun yanında Arabidopsis Atnoa1 (Atnos1) mutantında tıpkı yabani tipte olduğu gibi, stoma bekçi hücrelerindeki $\mathrm{H}_{2} \mathrm{O}_{2}$, NO'nun birikimini artırmıştır (Bright et al. 2006). Zhang et al. (2007), mısır bitkisi yaprak mezofil hücrelerinde hem $\mathrm{ABA}$ hem de $\mathrm{H}_{2} \mathrm{O}_{2}$ 'nin $\mathrm{NO}$ üretimini uyardığını; $\mathrm{H}_{2} \mathrm{O}_{2}$ 'nin $\mathrm{ABA}$-uyarımlı $\mathrm{NO}$ üretimi için gerekli olduğunu belirtmişlerdir. NO donorü SNP'nin, NO süpürücüsü veya $\mathrm{NO}$ sentez inhibitörünün, ABA-uyarımlı $\mathrm{H}_{2} \mathrm{O}_{2}$ miktarını etkilemediği bildirilmiştir (Zhang et al. 2007). Bu sonuçlar, $\mathrm{H}_{2} \mathrm{O}_{2}$ 'nin NO sentezini NR aktivitesi yoluyla gerçekleştirdiğini, fakat NO'nun $\mathrm{H}_{2} \mathrm{O}_{2}$ üretimine katkısının bulunmadığını göstermektedir.

$\mathrm{H}_{2} \mathrm{O}_{2}$ ve $\mathrm{NO}$ biyosentezi arasındaki bağlantının mekanizmaları açık olmamakla birlikte, ökaryotlarda hücre dışı uyarıcıların hücre içi yanıtlara dönüştürülmesinde MAPK (mitojen aktivasyonlu protein kinaz) kaskatı başlıca sinyalizasyon yolu olarak kabul edilmektedir. 
Arabidopsiste kök gelişimi esnasında $\mathrm{H}_{2} \mathrm{O}_{2}$ 'ye yanıt olarak $\mathrm{NO}$ üretimi ve sinyal transdüksiyonunun, MPK6 tarafından ayarlandığı bildirilmiştir (Wang et al. 2010b). Mısır yapraklarında ise $A B A$-uyarımlı $\mathrm{H}_{2} \mathrm{O}_{2}$ üretiminin NO oluşumunu sağladığı belirlenmiştir. MAPK'lar tarafından NO'nun aktivasyonu; ABA sinyalizasyonunda, antioksidant enzim aktivitelerinin ve ifadelerinin artışını sağladığı rapor edilmiştir (Zhang et al. 2007).

Son yıllarda araştırıcılar dışarıdan uygulanan $\mathrm{NO}$ ve/veya $\mathrm{H}_{2} \mathrm{O}_{2}$ 'nin, protein nitrozilasyonu ve karbonilasyonunu doğrudan etkilediğini gözlemlemişler; spesifik protein modifikasyonları ve oksidatif/nitrosatif sinyal iletimi arasında bir bağlantı olabileceğini ileri sürmüşlerdir (Jasid et al. 2008; Tanou et al. 2009b). Başka bir çalışmada da, Snitrosoglutatyon (GSNO) ve GSNO dekompozisyonunu katalizleyen Snitrosoglutatyonredüktazın (GSNOR), $\mathrm{H}_{2} \mathrm{O}_{2}$ ve NO metabolizmaları arasındaki karşılıklı etkileşimde anahtar elementler olabileceği vurgulanmıştır (Malik ve ark. 2011). Hücre içi bir NO kaynağı olan ve hücrenin her tarafında bulunan GSNO'nun, NO'nun S-nitrozilasyon reaksiyonu ile indirgenmiş glutatyon (GSH) üzerinden oluştuğu bildirilmiştir (Broniowska et al. 2013).

\section{NO ve $\mathrm{H}_{2} \mathrm{O}_{2}$ İlişkisinin Gen İfadesi ve Protein Aktivitelerinin Düzenlenmesindeki} Rolü

$\mathrm{H}_{2} \mathrm{O}_{2}$ ve $\mathrm{NO}$ arasında biyosentezleri aşamasındaki etkileşimden başka, bu iki maddenin protein aktivitelerinin ve gen ifadelerinin düzenlenmesi seviyesinde de karşılıklı etkileşim içerisinde bulundukları belirlenmiştir. Sinyal molekülleri olarak her iki molekül de bir grup genin ifadesini düzenlemektedir. Arabidopsis'te (Desikan et al. 2001a; Huang et al. 2002) ve tütün yapraklarında (Zago et al. 2006) yapılan transkriptom çalışmalarında, değişik stres koşullarında farklı süreçlerle ilişkili olan birçok gen tanımlanmış ve bu genlerin ifadesinin $\mathrm{H}_{2} \mathrm{O}_{2}$ ve NO tarafından düzenlendiği gösterilmiştir. Bu çalışmalar aynı zamanda gen ifadesi seviyesinde $\mathrm{NO}$ ve $\mathrm{H}_{2} \mathrm{O}_{2}$ arasında önemli bir etkileşim olduğunu yansıtmaktadır. Proteinlerin ve genlerin akışının düzenlenmesinde her iki molekülün de aynı süreçlere katıldığı gösterilmiştir. $\mathrm{NO}$ ve $\mathrm{H}_{2} \mathrm{O}_{2}$ 'nin metabolik yolunda mitojen aktivasyonlu protein kinaz (MAPK) kaskatı, fonksiyonel olabilir. $\mathrm{H}_{2} \mathrm{O}_{2}$, MAPK kaskatında NPK1'i aktive ederken (Grant et al. 2000; Desikan et al. 2001b); NO, tütünde SA-uyarımlı protein kinaz aktivitesini tetiklemektedir (Kumar and Klessig 2000). $\mathrm{H}_{2} \mathrm{O}_{2}$ 'nin tohum dormasisini ve çimlenmeyi, NO'nun katılımı için gerekli olan ve ABA'yı katabolize eden genleri teşvik ederek düzenlediği Liu et al. (2010b) tarafından açıklanmıştır. ABA-bağımlı $\mathrm{H}_{2} \mathrm{O}_{2}$ ve NO'nun kuraklık ve tuz toleransında SOD, CAT, APX ve GR gibi antioksidant enzimlerin aktivitesini ve transkripsiyonunu uyardığı bildirilmiştir (Lu et al. 2009; Zhang et al. 2009).

Doğrudan hedefleri ve gen ifadesi üzerindeki düzenleyici etkileri hakkındaki bilgiler açık olmasa da, bitkilerde NO ve ROS'ların bazı potansiyel hedefleri bilinmektedir. Katalaz ve peroksidaz gibi metal ve thiol içeren proteinler (Clarke et al. 2000), akonitaz (Navarre et al. 2000), glutatyon-S-transferaz, bakır/çinko süperoksitdismutaz, thioredoksin ve glutaredoksinin yanısıra glikoliz ile ilişkili enzimler ve S-adenozil-L-Met sentetazın, NO'nun başlıca hedefleri olduğu rapor edilmiştir (Lindermayr et al. 2005). ROS'ların ise glutatyon ya da thioredoksin gibi hücrenin redoks durumunu kontrol eden redoks-duyarlı moleküller üzerinde rol oynadığı ifade edilmiştir (Vraová et al. 2002). Gliseraldehit-3-fosfat-dehidrogenazın (GAPDH), Arabidopsis'te $\mathrm{H}_{2} \mathrm{O}_{2}$ 'nin inhibitör hedefi olduğu ve Arabidopsis'te $\mathrm{H}_{2} \mathrm{O}_{2}$ 'nin NO'nun hedefi olan metionin-adenil-transferazı (MAT) Cys kalıntılarını okside ederek inaktive ettiği bildirilmiştir (Lindermayr et al. 2005; Hancock et al. 2005; Wang et al. 2013). Ozon ( $\left.\mathrm{O}_{3}\right)$-uyarımlı $\mathrm{H}_{2} \mathrm{O}_{2}$ ve NO'nun tütünde patojen-ilişkili PR1a proteini ve fenilalanin amonyum liyaz (PALa), GPX, aminosiklopropankarboksilik asit sentaz (ACS2) gibi süpürücü proteinlerin transkripsiyonunu teşvik ettiği ifade edilmiştir (Pasqualini et al. 2009). NO ve ROS sinyal iletim yolundaki diğer genel aracılarının $\mathrm{Ca}^{2+}$ ve kalmodulin gibi $\mathrm{Ca}^{2+}$-bağlayan proteinler olduğu bildirilmiştir (Del Rìo et al. 2004; Mittler et al.2004).

Sinerjitik rollerine ilaveten $\mathrm{NO}$ ve $\mathrm{H}_{2} \mathrm{O}_{2}$, birçok metabolik yolda antagonistik etki de gösterebilir. $\mathrm{H}_{2} \mathrm{O}_{2}$ birikimi bitkilerde toksik olabilen kuvvetli bir oksidantken; NO, ROS süpürücü bir antioksidanttır. Yapılan bir çalışmada, Brassica juncea'da sitotoksik süreçlerin kadmiyumun neden olduğu ROS'lardan kaynaklanarak arttığı ifade edilmiştir. Dışarıdan NO uygulanmasının bitki hücrelerinde NO oluşumunu teşvik ettiği, $\mathrm{H}_{2} \mathrm{O}_{2}$ ve $\mathrm{Cd}$ streslerinin yol açtığı CAT, APX ve SOD enzim aktivitelerindeki azalmaları da 
düzelttiği bildirilmiştir (Verma et al. 2013). Benzer bulgular, buğday (Kopyra et al. 2006) ve soya fasulyesinde (Gropa et al. 2008) de bildirilmiştir. Yaprakların yaşlanması sırasında da $\mathrm{H}_{2} \mathrm{O}_{2}$ birikmekte ve yaşlanmayla ilişkili birçok genin (SAGs) ifadesini harekete geçiren pozitif bir düzenleyici olarak rol aldığı rapor edilmiştir (Smykowski et al. 2010).

\section{NO ve $\mathrm{H}_{2} \mathrm{O}_{2}$ Sinyal Alış Verişinin Diğer Sinyal Yolakları ile İlişkisi}

Hem $\mathrm{H}_{2} \mathrm{O}_{2}$ hem de NO'nun abiyotik stres sinyal yolları ile karşılıklı etkileşimine birden çok fitohormon aracilık etmektedir. Önceki çalışmalar, bitkilerde ABA'nın, SOD, CAT, APX ve glutatyon redüktaz (GR) gibi antioksidant enzim ifade ve aktivitelerini artırması için $\mathrm{H}_{2} \mathrm{O}_{2}$ ve NO'nun gerekli olduğunu göstermektedir (Sang et al. 2008; Zhang et al. 2009). MAPK kaskatının ve $\mathrm{Ca}^{2+} / \mathrm{CaM}$-bağımlı protein kinazlar da (CCaMK) ABA yanıtları ile ilgili olup $\mathrm{H}_{2} \mathrm{O}_{2}$ ve $\mathrm{NO}$ ile ilişkilidir. MAPK kaskatının, mısır bitkisinde $\mathrm{H}_{2} \mathrm{O}_{2}$ ve NO'nun üretimini düzenlediği ifade edilmiştir (Wang et al. 2010a; Ma et al. 2012).

Brassinosteroidler (BRs) düşük ve yüksek sıcaklıklar, kuraklık, tuzluluk ve ağır metal kirliliği gibi abiyotik streslere karşı bitkileri korumaktadır (Kagale et al.2007; Bajguz and Hayat 2009). $\mathrm{H}_{2} \mathrm{O}_{2}$ gibi ROS'ların sinyal molekülleri olarak, hıyar bitkisinde foto-oksidatif, soğuk streslerine ve hıyar mozayik virüsüne (CMV) karşı dayanıklılık ile BR-uyarımlı stres toleransına antioksidant enzim ifade ve aktivitelerini artırarak aracılık ettiği bildirilmiştir (Xia et al. 2009). Hıyar (Cucumis sativus) bitkisinde 24-epibrassinolid (EBR) uyarımlı NO üretimi için $\mathrm{H}_{2} \mathrm{O}_{2}$ 'nin gerekli olduğu; oysaki EBR-uyarımlı $\mathrm{H}_{2} \mathrm{O}_{2}$ üretimi için NO'nun mutlaka gerekli olmadığı bildirilmiş ve bu durum $\mathrm{H}_{2} \mathrm{O}_{2}$ ve NO süpürürücülerinin kullanıldığı farmakolojik deneyler ile kanıtlanmıştır (Cui et al.2011). Zhang et al. (2011), BR'nin NO üretimini aktive ederek $A B A$ biyosentezini harekete geçirme mekanizmasıyla mısır bitkisinde su stresine toleransı artırdığını açıklamışlardır.

Bir bitki hormonu olan etilen, çeşitli abiyotik stresler ile ilişkilidir (Guo and Ecker 2004). Mısır yapraklarında UV-B stresi altında etilen sentezininin teşvik edildiği, UV-B'nin ROS ile NO'daki artışları uyardığı gösterilmiş ve etilen sentezinin düzenlenmesinde ROS ile NO'nun sinerjistik etkiye sahip olduğu bildirilmiştir (Wang et al. 2006). Bu ilişki ayrıca stoma hareketleri sırasında $\mathrm{H}_{2} \mathrm{O}_{2}$, NO ve etilen sinyal iletimi arasında da kurulmuş, etilenin bakla bitkisinde peroksidaz-bağımlı $\mathrm{H}_{2} \mathrm{O}_{2}$ ve $\mathrm{NO}$ sentezi yoluyla gerçekleşen UV-B-uyarımlı stoma kapanmasına aracılık ettiği bildirilmiştir (Desikan et al. 2005; 2006; He et al. 2011a, b).

\section{Sonuçlar ve Öneriler}

Son yıllarda ilgi ile takip edilen moleküllerden olan $\mathrm{H}_{2} \mathrm{O}_{2}$ ve NO'nun, özellikle değişik stres durumlarında bitkilerdeki sinyal iletiminde temel rol oynadıkları ortaya konmuştur.

Her iki molekül de hücredeki konsantrasyonlarına bağlı olarak iki yönlü etki yapabilmektedir. Yüksek konsantrasyonlarda oksidatif ya da nitrosatif streslere neden olurken, düşük konsantrasyonlarda stres yanıtlarına aracılık eden sinyal molekülleri olarak görev yapmaktadır.

Bugüne kadar yapılan araştırmaların

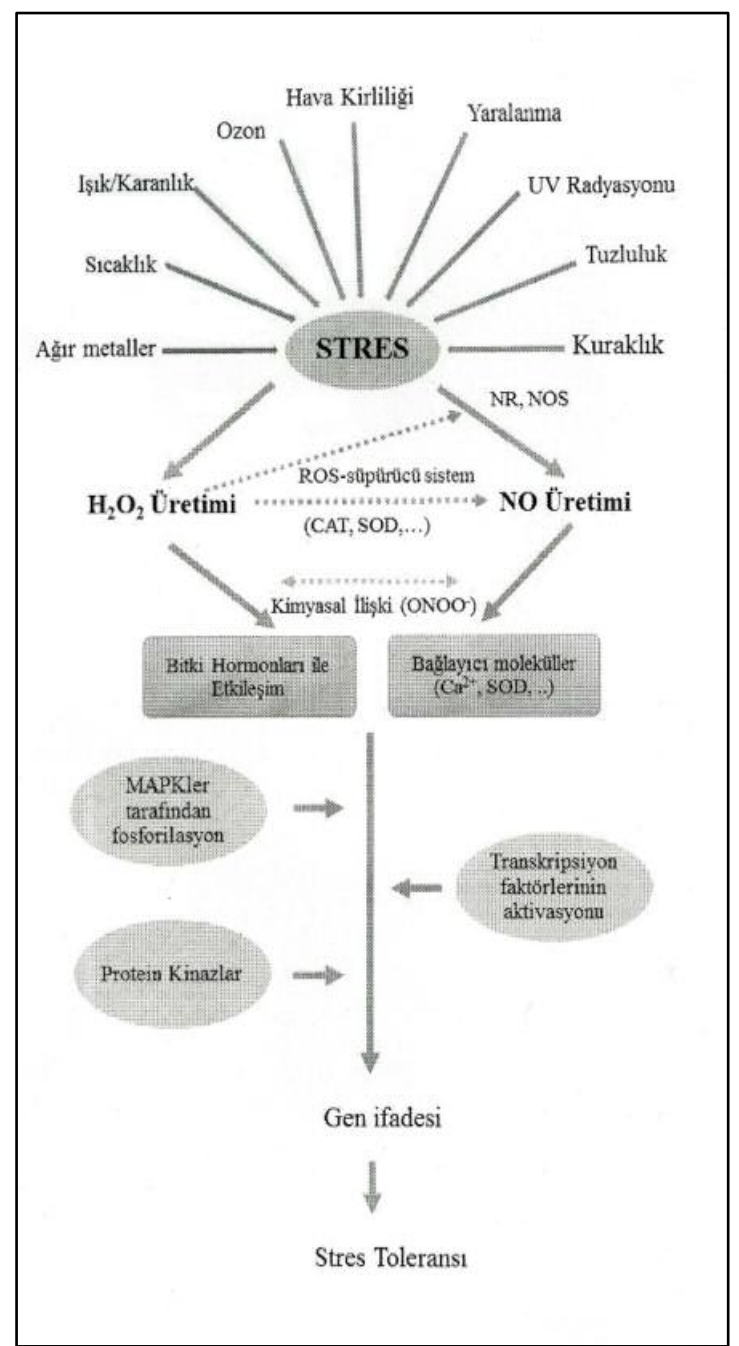

Şekil 3. Bitkilerde abiyotik stres yanıtlarında, NO ve $\mathrm{H}_{2} \mathrm{O}_{2}$ sinyal alış verişinin muhtemel yolları (Qiao et al. 2014'ten alınmıştır).

Figure 3. The possible pathways of $\mathrm{NO}$ and $\mathrm{H}_{2} \mathrm{O}_{2}$ signalling cross-talk in response to abiotic stress in plants (Qiao et al. 2014). 
sonuçları; iki molekül arasındaki biyolojik olarak aktif ve karşılıklı etkileşimin, değişik çevresel uyarıcılara verilen moleküler, hücresel ve tüm bitki yanıtlarını düzenlediğini göstermektedir.

NO'nun $\mathrm{H}_{2} \mathrm{O}_{2}$ ile etkileşimi sırasında gerçekleşen başlıca olaylar; 1) NO ile düzenlenmiş ROS-süpürücü sistemlerle ilişsili gen ifadeleri; 2) $\mathrm{O}_{2^{-}}$'nin $\mathrm{NO}$ ile peroksinitrit (ONOO-) formunu oluşturan reaksiyonu; 3 ) redoks-tabanlı post-traslasyonal protein modifikasyonları; 4) $\mathrm{NO}$ ve $\mathrm{H}_{2} \mathrm{O}_{2}$ 'nin, transkripsiyon faktörleri, iyon kanalları ve enzimler gibi proteinlerle doğrudan etkileşimleri olarak özetlenebilir (Şekil 3).

Biyolojik fonksiyonların tamamı için bu iki sinyal molekülünün, bitkiler tarafından kullanıldığı bilinen sinyal yollarındaki görevleri ile birbirleri arasındaki ilişki ve etkileşim yollarının açıklığa kavuşturulması gerekmektedir. Bundan sonra yapılacak çalışmaların önceliği, $\mathrm{H}_{2} \mathrm{O}_{2}$ ve NO'nun hücre içi konsantrasyonunu düzenleyen enzimlerin araştııılması ve bu enzimlerin doku/hücredeki yerlerinin belirlenmesi olarak düşünülebilir. Ayrıca $\mathrm{H}_{2} \mathrm{O}_{2}$ ve NO'nun hücreler tarafından nasıl algılandığı ve bunların transkripsiyon faktörleri, iyon kanalları ya da enzimler gibi hücresel proteinler ile ilişkisi daha detaylı araştııımalıdır.

Konu ile ilgili olarak hücre ve tüm bitki düzeyinde yapılacak fizyolojik, biyokimyasal ve moleküler çalışmalar, $\mathrm{H}_{2} \mathrm{O}_{2}$ ve NO'nun üretimi, bu iki molekülün karşılıklı sinyal alışveriş mekanizmalarının ve bitkilerde abiyotik stres yanıtları ile ilişkilerinin anlaşılmasına önemli katkılar sağlayacaktır.

\section{Kaynaklar}

Abogadallah G.M., 2010. Antioxidative defense under salt stress. Plant Signalling Behaviour, 5: 369_ 374

Avsian-Kretchmer O., Gueta-Dahan Y., Lev-Yadun S., Gollop R. and Ben-Hayyim G., 2004. The saltstress signal transduction pathway that activates the gpx1 pro-moter is mediated by intracellular $\mathrm{H}_{2} \mathrm{O}_{2}$, different from the pathway induced byextracellular $\mathrm{H}_{2} \mathrm{O}_{2}$ Plant Physiology, 135: 1685-1696

Bajguz A. and Hayat S., 2009. Effects of brassinosteroids on the plant responses to environmental stresses. Plant Physiology and Biochemistry, 47: 1-8

Banti V., Mafessoni, F., Loreti E., Alpi A. and Perata P., 2010. The heat-inducible transcription factor HsfA2 enhances anoxia tolerance in Arabidopsis. Plant Physiology, 152: 14711483
Beligni M. V. and Lamattina L. 1999. Is nitric oxide toxic or protective? Trends in Plant Science, 4 299-300

Besson-Bard A., Courtois C. and Gauthier A., 2008. Nitric Oxide in Plants: Production and crosstalk with $\mathrm{Ca}^{2+}$ signalling, Plant Molecular Biology, 1: 218-228

Bethke P. C., Badger M.R. and Jones R. L. 2004. Apoplastic synthesis of nitric oxide by plant tissues. Plant Cell, 16: 332-341

Blokhina O. and Fagerstedt KV., 2010. Reactive oxygen species and nitric oxide in plant mitochondria: origin and redundant regulatory systems. Physiologia Plantarum, 138:447-462

Bouchard J.N. and Yamasaki H., 2009. Implication of nitric oxide in the heat-stress-induced cell death of the symbiotic alga Symbiodinium microadriaticum Marine Biology 156: 22092220

Bright J., Desikan R., Hancock J.T., Weir I.S., Neill, S.J., 2006. ABA-induced NO generation and stomatal closure in Arabidopsis are dependent on $\mathrm{H}_{2} \mathrm{O}_{2}$ synthesis. The Plant Journal. 4: 113-122

Broniowska K. A., Diers A.R. and Hogg N., 2013. S Nitrosoglutathione. Biochimica et Biophysica Acta, 1830: 3173-3181

Büyük I., Soydam-Aydın S. ve Aras S., 2012. Bitkilerin Tuz Stresine Verdiği Moleküler Cevaplar, Türk Hijyen ve Deneysel Biyoloji Dergisi, 69 (2): 97-110

Clarke A., Desikan R., Hurst R.D., Hancock, J.T. and Neill, S.J., 2000. NO way back: nitric oxide and programmed cell death in Arabidopsis thaliana suspension cultures. The Plant Journal, 24: 667-677

Cooney R.V., Harwood P.J., Custer L.J. and Franke A.A. 1994. Light mediated conversion of nitrogen dioxide to nitric oxide by carotenoids. Environ Health Perspectives, 102:460-462

Corpas F.J., Barroso J.B. and Carreras A., 2004. Cellular and subcellular localization of endogenous nitric oxide in young and senescent pea plants. Plant Physiology, 136:2722-2733

Cui X.M., Zhang Y.K., Wu X.B. and Liu C.S., 2010. The investigation of the alleviated effect of copper toxicity by exogenous nitric oxide in tomato plants. Plant Soil and Environment, 56: 274-281

Cui J., Zhou Y., Ding J., Xia X., Shi K., Chen S., Asami T., Chen Z. and Yu, J., 2011. Role of nitric oxide in hydrogen peroxide-dependent induction of abiotic stress tolerance by brassinosteroids in cucumber. Plant Cell and Environment, 34: 347-358 
Del Rìo L.A., Corpas F.J. and Barroso J.B., 2004. Nitric oxide and nitric oxide synthase activity in plants. Phytochemistry 65: 783-792

Delledonne M., Xia Y.J., Dixon R.A. and Lamb, C., 1998. Nitric oxide functions as a signaling in plant disease resistance. Nature, 39: 585-588

Delledonne M., 2005. NO news is good news for plants. Current Opinion in Plant Biology, 8: 390-396

Desikan R., Mackerness S.A-H., Hancock J.T. and Neill S.J., 2001a. Regulation of the Arabidopsis transcriptome by oxidative stress. Plant Physiology, 127:159-172

Desikan R., Hancock J.T., Ichimura K., Shinozaki K. and Neill S.J., 2001b. Harpin induces activation of the Arabidopsis mitogenactivated protein kinases AtMPK4 and AtMPK6. Plant Physiology, 126: 1579-1587

Desikan R., Cheung M.K., Bright J., Henson D., Hancock J.T. and Neill S.J., 2004. ABA, hydrogen peroxide and nitric oxide signaling in stomatal guard cell. Journal of Experimental Botany, 395: 205-212

Desikan R., Hancock J.T., Bright J., Harrison J., Weir I., Hooley R. and Neill S.J., 2005. A role for ETR1 in hydrogen peroxide signaling in stomatal guard cells. Plant Physiology, 137: 831-834

Desikan R., Last K., Harrett-Williams R., Tagliavia C., Harter, K., Hooley, R., Hancock J.T. and Neill S.J., 2006. Ethylene-induced stomatal closure in Arabidopsis occurs via AtrbohF-mediated hydrogen peroxide synthesis. The Plant Journal, 47: 907-916

Esim N. and Atıcı Ö., 2015, Effects of exogenous nitiric oxide and salicylic acid on chillinginduced oxidative stress in wheat (Triticum aestivum), Frontiers in Life Science, 8(2): 124-130

Esim N. and Atıcı Ö., 2014. Nitric oxide improves chilling tolerance of maize by affecting apoplastic antioksidative enzymes in leaves, Plant Growth Regulation, 72: 29-38

Esim N., Atıcı Ö. and Mutlu S., 2014. Effects of exogenous nitric oxide in wheat seedlings under chilling stress, Toxicology and Industrial Health, 30(3): 268-274

Esim N. and Atıcı Ö., 2013, Nitric oxide alleviates boron toxicity by reducing oxidative damage and growth inhibition in maize seedlings, Australian Journal of Crop Sciences, 7(8): 1085-1092
Fan H., Guo S., Jiao Y., Zhang R. and Li J., 2007. Effects of exogenous nitric oxide on growth, active oxygen species metabolism, and photosynthetic characteristics in cucumber seedlings under $\mathrm{NaCl}$ stress. Frontiers of Agriculture in China 1: 308-314

Foyer C.H. and Noctor, 2011. Ascorbate and glutathione: the heart of the redox hub. Plant Physiology, 155: 2-18

Gould K.S., Lamotte O., Klinguer A., Pugin A. and Wendehenne D., 2003. Nitric oxide production in tobacco leaf cells: a generalized stress response? Plant Cell \& Environment, 26: 1851-1862

Grant J.J., Yun B.-W. and Loake G.J., 2000. Oxidative burst and cognate redox signaling reported by luciferase imaging: identification of a signal network that functions independently of ethylene, SA and Me-JA but is dependent on MAPKK activity. The Plant Journal, 24: 569-582

Gropa M.D., Rosales E.P., Lannone M.F. and Benavides M.P., 2008. Nitric oxide, polyamines and $\mathrm{Cd}$ induced phytotoxicity in wheat roots. Phytochemistry, 69: 2609-2615

Guo H. and Ecker J.R., 2004. The ethylene signaling pathway: new insights. Current Opinion in Plant Biology, 7: 40-49

Guo F.Q., Okamoto M. and Crawford N.M., 2003. Identification of a plant nitric oxide synthase gene involved in hormonal signaling. Science, 302, 100-103

Halliwell B., 1984. Toxic effects of oxygen in plant tissues, In: Chloroplast Metabolism, The structure and function of chloroplasts in green leaf cells. Oxford Press, Oxford, 180-206

Halliwell B. and Gutteridge J.M.C. 2007. Free Radicals in Biology and Medicine. $4^{\text {th }}$ ed., Oxford University Press, Oxford

Hancock J.T., Henson D., Nyirendam M., Desikan R., Harrison J., Lewis M., Hughes J. and Nefill S.J., 2005. Proteomic identification of glyceraldehyde 3-phosphate dehydrogenase as an inhibitory target of hydrogen peroxide in Arabidopsis. Plant Physiology and Biochemistry, 43: 828-835

Hao G.P., Xing Y. and Zhang J.H., 2008. Role of nitric oxide dependence on nitric oxide synthase-like activity in the water stress signalling of maize seedling. Journal of Integrative Plant Biology, 50: 435-442

He J.M., Xu H., She X.P., Song X.G. and Zhao W.M., 2005. The role and the interrelationship of hydrogen peroxide and nitric oxide in the UVB-induced stomatal closure in broad bean. Functional Plant Biology, 32: 237-247 
He J.M., Yue X.Z., Wang R.B. and Zhang Y., 2011a. Ethylene mediates UV-B-induced stomatal closure via peroxidase-dependent hydrogen peroxide synthesis in Vicia faba L. Journal of Experimental Botany, 62: 2657-2666

He J.M., Zhang Z., Wang R.B. and Chen Y.P., 2011b. UV-B-induced stomatal clo-sure via ethylenedependent NO generation in Vicia faba, Functional Plant Biology 38,293-302

Henry Y. A., Ducastel B. and Guissani A., 1996. Basic chemistry of nitric oxide and related nitrogen oxides. In: Nitric oxide research from chemistry to biology. Springer, USAHsu Y.T., Kao C.H., 2004. Cadmium toxicity is reduced by nitric oxide in rice leaves. Plant Growth Regulation, 42: $227-238$

Hsu Y.T. and Kao C.H., 2004. Cadmium toxicity is reduced by nitric oxide in rice leaves Plant Growth Regulation., 42: 227-238

Hu K.D., Hu L.Y., Li Y.H., Zhang F.Q., Zhang H., 2007. Protective roles of nitric oxide on germination and antioxidant metabolism in wheat seeds under copper stress. Plant Growth Regulation, 53: 173-183

Huang X., von Rad, U. and Durner, J., 2002. Nitric oxide induces transcriptional activation of the nitric oxide-tolerant alternative oxidase in Arabidopsis suspension cells. Planta 215, 914-923

Jasid S., Simontacchi M., Bartoli C.G. and Puntarulo S., 2006. Chloroplasts as a nitric oxide cellular source. Effect of reactive nitrogen species on chloroplastic lipidsand proteins. Plant Physiology, 142: 1246-1255

Jubany-Marí T., Munne B.S. and Alegre L., 2010. Redox regulation of water stress responses in field-grown plants. Role of hydrogen peroxide and ascorbate. Plant Physiology and Biochemistry, 48: 351-358

Kagale S., Divi U.K., Krochko J.E., Keller W.A. and Krishna P., 2007. Brassinosteroid confers tolerance in Arabidopsis thaliana and Brassica napus to a range of abiotic stresses. Planta, 225: 353-364

Kaya C., Sönmez O., Ashraf M., Polat T., Tuna L. and Aydemir S., 2015. Exogenous application of nitric oxide and thiourea regulates on growth and some key physiological processes in maize (Zea mays L.) plants under saline stress. Soil-Water Journal, Special Issue: 61-66

Khan M.N., Mobin M., Mohammad F. and Corpas F.J., Nitric oxide action in abiotic stress responses in plants. 2015, Springer International Publishing Switzerland. 100102
Klatt P. and Lamas S. 2000. Regulation of protein function by $S$-gluthiolation in response to oxidative and nitrosative stress, European Journal of Biochemistry, 267: 4928- 4944

Kolbert Z., Bartha B. and Erdei L., 2005. Generation of nitric oxide in roots of Pisum sativum, Triticum aestivum and Petroselinum crispum plants under osmotic and drought stress. Acta Biologica Szegediensis, 49: 13-16

Königshofer H., Tromballa H.W. and Löppert H.G., 2008. Early events in signaling hightemperature stress in tobacco BY2 cells involve alterations in membranefluidity and enhanced hydrogen peroxide production. Plant Cell and Environment, 31: 1771-1780

Kopyra M. and Gwó'zd'z E.A., 2003. Nitric oxide stimulates seed germination and coun-teracts the inhibitory effect of heavy metals and salinity on root growth of Lupinus luteus. Plant Physiology and Biochemistry, 41: 1011-1017

Kopyra M., Stachon-Wilk M. and Gwó'zd'z E.A., 2006. Effects of exogenous nitric oxide on the antioxidant capacity of cadmium-treated soybean cell suspension. Acta Physiologiae Plantarum, 28: 525-536

Kumar D. and Klessig D.F., 2000. Differential induction of tobacco MAP kinases by the defense signals nitric oxide, salicylic acid, ethylene, and jasmonic acid. Molecular Plant-Microbe Interactions Journal, 13: 347-351

Larkindale J. and Knight M.R., 2002. Protection against heat stress-induced oxidative damage in Arabidopsis involves calcium, abscisic acid, ethylene, and salicylic acid. Plant Physiology, 128: 682-695

Leshem Y.Y. and Haramaty E., 1996. The characterization and contrasting effects of the nitric oxide free radical in vegetative stress and senescence of Pisum sativum Linn. foliage. Journal of Plant Physiology, 148: 258-263

Li Q.Y., Niu H.B., Yin J., Wang M.B., Shao H.B., Deng D.Z., Chen X.X., Ren J.P. and Li, Y.C., 2008 Protective role of exogenous nitric oxide against oxidative-stress induced by salt stress in barley (Hordeum vulgare). Colloids and Surfaces Biointerfaces, 65: 220-225

Liao W., Huang G., Yu J. and Zhang M., 2012. Nitric oxide and hydrogen peroxide alleviate drought stress in marigold explants and promote its adventitious root development. Plant Physiology and Biochemistry, 58: 6-15 
Lin Y.F. and Aarts M.G., 2012. The molecular mechanism of zinc and cadmium stress response in plants. Cellular and Molecular Life Sciences, 69: 3187-3206

Lindermayr C., Saalbach G. and Durner J., 2005. Proteomic identification of S-nitrosylated proteins in Arabidopsis. Plant Physiology, 137: 921-930

Liu H., Lau E., Lam M.P.Y., Chu H., Li, S., Huang G., Guo P., Wang J., Jiang L., Chu I.K., Lo C. and Tao Y., 2010a. OsNOA1/RIF1 is a functional homolog of AtNOA1/RIF1: implication for a highly conserved plant cGTPase essential for chloroplast func-tion. New Phytologist, 187: 83-105

Liu Y., Ye N., Liu R., Chen M. and Zhang J., 2010b. $\mathrm{H}_{2} \mathrm{O}_{2}$ mediates the regulation of $A B A$ catabolism and GA biosynthesis in Arabidopsis seed dormancy and germination. Journal of Experimental Botany, 61: 2979-2990

Lu S., Su, W., Li H. and Guo Z., 2009. Abscisic acid improves drought tolerance of triploid bermudagrass and involves $\mathrm{H}_{2} \mathrm{O}_{2}$ - and NOinduced antioxidant enzyme activities. Plant Physiology and Biochemistry, 7: 132-138

Lum H.K., Butt Y.K.C. and Lo S.C.L., 2002. Hydrogen peroxide induces a rapid production of nitric oxide in mung bean (Phaseolus aureus). Nitric Oxide, 6: 205-213

Ma F., Lu R., Liu H., Shi B., Zhang J., Tan, M., Zhang, A. and Jiang, M., 2012. Nitric oxide-activated calcium/calmodulin-dependent protein kinase regulates the abscisic acid-induced antioxidant defence in maize. Journal of Experimental Botany, 63: 4835-4847

Malik S. I., Hussain A., Yun B.W., Spoel S.H. and Loake G.J., 2011. GSNOR-mediated denitrosylation in the plant defence response. Plant Science, 181: 540-544

Mazid M., Khan T.A. and Mohammad F., 2011. Role of nitric oxide in regulation of $\mathrm{H}_{2} \mathrm{O}_{2}$ mediating tolerance of plants to abiotic stress: a synergistic signaling approach. Journal of Stress Physiology \& Biochemistry, 7: 34-74

Mittler R., Vanderauwera S., Gollery M. and Van Breusegem F., 2004. Reactive oxygen gene network of plants. Trends in Plant Science, 9: 490-498

Mittler, R., 2002. Oxidative Stress, Antioxidants and Stress Tolerance, Trends in Plant Science, 7: 405-410

Molassiotis A. and Fotopoulo V., 2011. Oxidative and nitrosative signaling in plants,two branches in the same tree? Plant Signalling Behaviour, 6: 210-214
Mutlu F. and Yürekli F., 2015. Analysis of interactions of nitric oxide and polyamine under cadmium stress in wheat. Turkish Journal of Botany, 39: 778-785

Navarre D.A., Wendehenne D., Durner J., Noad R. and Klessig D.F., 2000. Nitric oxide modulates the activity of tobacco aconitase. Plant Physiology, 122: $573-582$

Neill S.J., Desikan R., Clarke A. and Hancock J.T., 2002a. Nitric oxide is a novel component of abscisic acid signaling in stomatal guard cells. Plant Physiology, 128: 13-16

Neill S.J., Desikan R. and Clarke A., 2002b. Hydrogen peroxide and nitric oxide as signaling molecules in plants. Journal of Experimental Botany, 53: 1237-1242

Neill S., Desikan R. and Hancock J.T., 2002c. Hydrogen peroxide signalling. Current Opinion in Plant Biology, 5(5): 388-395.

Neill S., Desikan R. and Hancock J.T., 2003. Nitric oxide signalling in plants. New Phytologist, 159 $11-35$

Pasqualini S., Meier S., Gehring C., Madeo L., Fornaciari M., Romanoand B. and Ederli L., 2009. Ozone and nitric oxide induce cGMPdependent and independent transcription of defence genes in tobacco. New Phytologist, 181: $860-870$

Qiao W.H., Xiao S.H., Yu L. and Fan L.M., 2009 Expression of a rice gene OsNOA1 reestablishes nitric oxide synthesis and stressrelated gene expression for salttolerance in Arabidopsis nitric oxide-associated 1 mutant Atnoa1. Environmental and Experimental Botany, 65: 90-98

Qiao W., Li C. and Fan L-M., 2014. Cross-talk between nitric oxide and hydrogen peroxide in plant responses to abiotic stresses, Environmental and Experimental Botany, 100: 84-93

Rockel P., Strube F., Rockel A., Wildt J. and Kaiser, W.M., 2002. Regulation of Nitric Oxide (NO) Production by Plant Nitrate Reductase in vivo and in vitro, Journal of Experimental Botany, (53):103-110

Sang J., Zhang A., Lin F., Tan M. and Jiang M., 2008. Cross-talk between calcium-calmodulin and nitric oxide in abscisic acid signaling in leaves of maize plants. Cell Research, 18: 577-588

Santa-Cruz D.M., Pacienza N.A., Polizio A.H. and Balestrasse K.B., Tomaro M.L., Yannarelli G.G. 2010. Nitric oxide synthase-like dependent NO production enhances heme oxygenase upregulation in ultraviolet-B-irradiated soybean plants. Phytochemistry, 71: 1700-1707 
Shi S., Wang G., Wang Y., Zhang L. and Zhang L., 2005. Protective effect of nitric oxide against oxidative stress under ultraviolet-B radiation. Nitric Oxide, 13: 1-9

Singh H.P., Batish D.R., Kaur G., Arora K. and Kohli R.K., 2008. Nitric oxide (as sodium nitroprusside) supplementation ameliorates $\mathrm{Cd}$ toxicity in hydroponically grown wheat roots. Environmental and Experimental Botany, 63: 158-167

Ślesak I., Libik M., Karpinska B., Karpinski S. and Miszalski Z., 2007. The Role of Hydrogen Peroxide in Regulation of Plant Metabolism and Cellular Signalling in Response to Environmental Stresses. Acta Biochimica Polonica, 54: 39-50

Smykowski A., Zimmermann P. and Zentgraf U., 2010. G-Box binding factor 1 reduces CATALASE 2 expression and regulates the onset of leaf senescence in Arabidopsis. Plant Physiology, 153: $1321-1331$

Song L., Ding W., Zhao M., Sun B. and Zhang L., 2006. Nitric oxide protects against oxidative stress under heat stress in the calluses from two ecotypes of reed. Plant Science, 171: $449-458$

Suzuki N. and Mittler R., 2006. Reactive oxygen species and temperature stresses: adelicate balance between signalling and destruction. Physiologia Plantarum, 126: 45-51

Tanou G., Molassiotis, A. and Diamantidis, G., 2009a. Induction of reactive oxygen species and necrotic death-like destruction in strawberry leaves by salinity. Environmental and Experimental Botany, 65: 270-281

Tanou G., Job C., Rajjou L., Arc E., Belghazi M., Diamantidis G., Molassiotis A. and Job D., 2009b. Proteomics reveals the overlapping roles of hydrogen peroxide and nitric oxide in the acclimation of citrus plants to salinity. The Plant Journal, 60: 795-804

Tian Q.Y., Sun D.H., Zhao M.G. and Zhang W.H., 2006. Inhibition of nitric oxide synthase (NOS) underlies aluminum-induced inhibition of root elongation in Hibiscus moscheutos. New Phytologist, 174: 322-331

Tossi V., Lamattina L. and Cassia R., 2009. An increase in the concentration of abscisic acid is critical for nitric oxide mediated plant adaptive responses to UV-B irradiation. New Phytologist, 181: 871-879

Uchida A., Jagendorf A.T., Hibino T., Takabe T. and Takabe T., 2002. Effects of hydrogen peroxide and nitric oxide on both salt and heat stress tolerance in rice. Plant Science, 163: $515-523$
Unsal NP. and Arısan D., 2009. Nitric Oxide Signalling in Plants, The Botanical Review, 75 (2): 203-229

Verma K., Mehta S.K. and Shekhawat G.S., 2013. Nitric oxide (NO) counteracts cadmium induced cytotoxic processes mediated by reactive oxygen species (ROS) in Brassica juncea: cross-talk between ROS, NO and antioxidant responses. Biometals, 26: 255-269

Volkov R.A., Panchuk I.I. and Mullineaux P.M., Schöffl F., 2006. Heat stress-induced $\mathrm{H}_{2} \mathrm{O}_{2}$ is required for effective expression of heat shock genes in Arabidopsis. Plant Molecular Biology, 61: 733-746

Vraová E., Inzé D. and Van Breusegem F., 2002. Signal transduction during oxidative stress. Journal of Experimental Botany, 53: 12271236

Wahid A., Perveen M., Geelani S. and Basra S.M.A., 2007. Pretreatment of seed with $\mathrm{H}_{2} \mathrm{O}_{2}$ improves salt tolerance of wheat seedlings by alleviation of oxidative damage and expression of stress proteins. Journal of Plant Physiology, 164: 283-294

Wang Y.S. and Yang Z.M., 2005. Nitric oxide reduces aluminum toxicity by preventingoxidative stress in the roots of Cassia tora L. Plant Cell Physiology, 46: 1915-1923

Wang Y., Feng H., Qu Y., Cheng J., Zhao Z., Zhang M., Wang X. and An L., 2006. The relationship between reactive oxygen species and nitric oxide in ultraviolet-B-induced ethylene production in leaves of maize seedlings. Environmental and Experimental Botany, 57: $51-61$

Wang H., Liang X., Wan Q., Wang X. and Bi Y., 2009 Ethylene and nitric oxide are involved in maintaining ion homeostasis in Arabidopsis callus under salt stress. Planta, 230: 293-307

Wang L., Yang L., Yang F., Li X., Song Y., Wang X. and $\mathrm{Hu} X ., 2010 a$. Involvements of $\mathrm{H}_{2} \mathrm{O}_{2}$ and metallothionein in NO-mediated tomato tolerance to copper toxicity. Journal of Plant Physiology, 167: 1298-1306

Wang P., Du Y., Li Y., Ren D. and, Song C., 2010b. Hydrogen peroxide-mediated activation of MAP kinase 6 modulates nitric oxide biosynthesis and signal transduction in Arabidopsis. Plant Cell, 22: 2981-2998

Wang Y., Ries A., Wu K., Yang A. and Crawford N.M., 2010c. The Arabidopsis pro-hibitin gene phb3 functions in nitric oxide-mediated responses and in hydrogen peroxide-induced nitric oxide accumulation. Plant Cell, 22: 249-259 
Wang Y., Lin A., Loake G.J. and Chu C., 2013. $\mathrm{H}_{2} \mathrm{O}_{2}-$ induced leaf cell death and thecrosstalk of reactive nitric/oxygen species. Journal of Integrative Plant Biology, 55: 202-208

Wendehenne D, Gould K. and Lamotte O., 2004. Nitric oxide is a essential component of biotic and abiotic stress-induced signaling pathways in plants. In: Magalhaes JR (ed) Nitric oxide signaling in higher plants. Studium Press, Houston, 55-64

Xia X.J., Wang,Y.J., Zhou,Y.H., Tao,Y., Mao W.H., Shi K., Asami T., Chen Z. and Yu J.Q., 2009. Reactive oxygen species are involved in brassinosteroid-induced stress tolerance in cucumber. Plant Physiology, 150: 801-814

Xiong J., An L., Lu H. and Zhu C., 2009. Exogenous nitric oxide enhances cadmium tolerance of rice by increasing pectin and hemicelluloses contents in root cellwall. Planta, 230: 755-765

Xiong J., Fu, G., Tao, L. and Zhu, C., 2010. Roles of nitric oxide in alleviating heavy metal toxicity in plants. Archives of Biochemistry and Biophysics.497: 13-20

Xuan Y., Zhou S., Wang L., Cheng Y. and Zhao L., 2010. Nitric oxide functions as a signal and acts upstream of AtCaM3 in thermotolerance in Arabidopsis seedlings. Plant Physiology, 153: $1895-1906$

Zago E., Morsa S., Dat J.F., Alard P., Ferrarini A., Inze D., Delledonne M. and Breusegem F.V., 2006. Nitric oxide and hydrogen peroxideresponsive gene regulation during cell death induction in tobacco. Plant Physiology, 141: 404-411

Zhang Y., Wang L., Liu Y., Zhang Q., Wei Q. and Zhang W., 2006. Nitric oxide enhances salt tolerance in maize seedlings through increasing activities of proton-pumpand $\mathrm{Na}+/ \mathrm{H}+$ antiport in the tonoplast. Planta, 224: 545-555

Zhang A., Jiang M., Zhang J., Ding H., Xu S., Hu X. and Tan M., 2007. Nitric oxide induced by hydrogen peroxide mediates abscisic acidinduced activation of the mitogen activated protein kinase cascade involved in antioxidant defense in maize leaves. New Phytologist, 175: 36-50
Zhang H., Li, Y.H., Hu, L.Y., Wang, S.H., Zhang F.Q. and Hu K.D., 2008. Effects of exoge-nous nitric oxide donor on antioxidant metabolism in wheat leaves under aluminum stress. Russian Journal of Plant Physiology, 55: 469-474

Zhang Y., Tan J., Guo Z., Lu S., He S., Shu, W. and Zhou, B., 2009. Increased abscisic acid levels in transgenic tobacco over-expressing 9 cis-epoxycarotenoid dioxygenase influence $\mathrm{H}_{2} \mathrm{O}_{2}$ and $\mathrm{NO}$ production and antioxidant defences. Plant Cell and Environment, 32: 509-519

Zhang A., Zhang J., Zhang J., Ye N., Zhang H., Tan M. and Jiang M., 2011. Nitric oxide mediates brassinosteroid-induced ABA biosynthesis involved in oxidative stress tolerance in maize leaves. Plant Cell Physiology, 52: 181-192

Zhao L., Zhang F., Guo J., Yang Y., Li B. and Zhang L., 2004. Nitric oxide functions as asignal in salt resistance in the calluses from two ecotypes of reed. Plant Physiology, 134: 849-857

Zhao M., Zhao X., Wu Y. and Zhang L., 2006. Enhanced sensitivity to oxidative stress in Arabidopsis nitric oxide synthase mutant. Journal of Plant Physiology, 164: 737-745

Zhao M.G., Tian Q.Y. and Zhang W.H., 2007. Nitric oxide synthase dependent nitric oxide production is associated with salt tolerance in Arabidopsis. Plant Physiology, 144: 206217

Zhao M.G., Chen L., Zhang L.L. and Zhang W.H., 2009. Nitric reductase dependent nitric oxide production is involved in cold acclimation and freezing tolerance in Arabidopsis. Plant Physiology, 151: 755-767 